\title{
Blut : Blood Donation Application
}

\author{
Sajith T, Santhose D, Senthalan S, Vasanth V \\ UG Scholar, Department of Computer Science and Engineering, Akshaya College of Engineering and \\ Technology, Coimbatore, Tamil Nadu, India
}

\begin{abstract}
Article Info

Volume 7, Issue 2

Page Number: 335-341

Publication Issue :

March-April-2021

Article History

Accepted : 12 April 2021

Published : 17 April 2021

Blood Donation Management System is an android application that brings voluntary blood donors and those in need of blood on to a common platform. The mission is to fulfil every blood request in the country with a Promising android application and motivated individuals who are willing to donate blood. The proposed work aims to overcome the communication barrier between donors and receivers and aims to encourage people to donate blood by providing motivational videos and quotes in the app. This project will contain details about medical history of the donors and blood camps. We also aim to create misconceptions that people has regarding blood donation. This project aims at servicing the persons who seek donors who are willing to donate blood and also provide it in the time frame required. Blood Donation Management System tries to assist Victims/patients/those in want of blood. It is an endeavor to achieve dead set these people in want of blood and connect them to those willing to donate. The proposed work explores to find blood donors by using the blood group and address they have filled during registration

Keywords : Android, Blood Donation Management System, Medical History, Mobile Application, Web Application.
\end{abstract}

\section{INTRODUCTION}

The development of a Blut - Blood Donation System depends on Mobile application. All Clinic System should have patient and donor information control matcher system. Nowadays, computers are the most useful for all fields; they can also stand for information distributing, catching, matching, etc. All doctors who are system's members can see donors' and patients' data and matching information. The health systems using Mobile application were aided human beings. In this system, blood matcher can help donors' and patients' to get the best matcher. The establishment of Mobile Application for blood donation system is to encourage blood donor society. The registered donors will get notification about the blood donation needed at a specific clinic where they can go and donate.

The Dashboard Contains "Profile", "Donate", "Find Donor", "Blood Bank", "Details", “About". Blut application provides donors with functionalities 
including "blood request feed", "donation history", "invite friend", "book an appointment" and "Rewards" (with the clinic to donate blood), at the same time the requester can send requests and use this application to maintain the different blood donation activities.

Admin and User will add the details of the willing donors through surveys and data from various organizations. The admin will keep track of the registered user and verify whether the user is fake or not. If the registered user is fake, then we can remove the user and we can also hide the registered user if the user is not eligible to donate. Blood Donation Management System is an android application that brings voluntary blood donors and those in need of blood on to a common platform. The mission is to fulfil every blood request in the country with a promising android application and motivated individuals who are willing to donate blood. The proposed work aims to overcome the communication barrier between donors and receivers and aims to encourage people to donate blood by providing motivational videos and quotes in the app. This project will contain details about medical history of the donors and blood camps. We also aim to create misconceptions that people has regarding blood donation. This project aims at servicing the persons who seek donors who are willing to donate blood and also provide it in the time frame required. Blood Donation Management System tries to assist victims/patients/those in want of blood. It is an endeavour to achieve dead set these people in want of blood and connect them to those willing to donate. The proposed work explores to find blood donors by using the blood group and address they have filled during registration. The vision is to be "The hope of every person in search of a voluntary blood donor"

\section{RELATED WORK}

A) A Survey Paper on E-Blood Bank and an Idea to use on Smartphone.

Blood is an important aspect for all living things. It proves to be a lifesaving component in case of emergency requirement. None of the online blood bank offers the direct contact between donor and blood bank. This is the major drawback of the existing system. Existing systems are time consuming; require more manpower and it is costly. The new idea will improve the existing system and it will move from conventional desktop system to mobile system. E-blood bank is an integrated blood bank automation system. The main purpose of E-blood bank is to interconnect all the blood banks of the state into a single network, validation, storage and circulation of various live data and information by using computation technology. The data which is stored on the computing devices will help the public for easy access to the blood availability status in blood banks on fingertips so that he can place a request or notify particular blood group in nearby blood bank save a valuable life.

\section{B) The Optimization of Blood Donor Information and Management System}

Blood is a saver of all existing lives in case of emergency needs. The objective of the project is to provide general Public with blood donors at real time. This project is a online blood bank system that is achieved on an android platform. The android application will help users to view and access information such as the nearby hospitals and the blood banks and the availability of blood banks. The App will contain names, address, contact and blood type of blood donors available nearby from the persons in need of blood. This application uses GPS to track the donors and nearby blood banks. Hence due to the availability of blood donors and hospitals 
nearby in a single touch of the hand. The reduction in time is to a great extent, the user can search for the required blood from the nearest blood donors, blood banks and hospitals. To make a quick decisions that might save the life The application will register and verify the users who will be the person in need of blood and donor

\section{C) Donor Management}

Intuitive and intelligent donor form for capturing details like Donor Questionnaire, Medical Examination, Blood Collection Details and Serology Report. The system allows automatic component data generation based on the component selected in the blood donor form. The system allows bulk update for serology for blood units. Serology result for many donors can be updated at once. The system allows for either component creation before serology test or vice versa. Based on the serology test, the component created are updated automatically The system allows bar-coded blood bag number entry All donor related reports are excel downloadable All Reports provides filtering over many factors like Blood Group, gender, area, blood Camp, date of donation, donor type etc. The system provides easy link for easy edit or adding details for various sections of the donor form During form filling, the system notifies the user how much percentage of donor data has been updated The donor form is highly configurable and can be easily modified to include additional data required by various blood banking institutions

D) Managing Practical Solutions for Blood Bank Management

The system allows components to be created before serology and vice-versa. The system takes care to automatically update the components when serology is done. Automatic creation of components from the donor form as well as manual component creation. Checks in place to ensure that a component for which cross-match is not done does not get issued.
Automated deferral for a donor is medical evaluation for a donor fails. Based on serology details, components are auto marked as discard when serology fails and the system does not allow them to be issued. The system prevents final bill generation for patients if the payment has not been accounted for.The system provides configurable cost for patients from Govt and Private Centres.The system allows discounts to be given for patients as well as free issue to patients. Final Bill, Component Label, Cross Match Report - Auto Generated as per institution requirements

\section{E) Blood Donation Management System}

It is a web enabled and mobile-based application to maintain day to day transactions in a blood bank. This application is to create Information about the donor and organization that are related to donating the blood. This software help to register all the donors, Blood collection details, blood issued details etc. When registration is completed, a user becomes a donor who will be able to open an account providing fundamental information with email ID and Password. They can modify their account information by updating username, Facebook ID, mobile number and profile picture. If donors are eager to donate blood they can confirm the system [8]. They can remove their account from the system if they wish for. In this application, Admin is the main authority who can add, delete, and modify information if required. A user is able to search donor from the home page. This application provides search facilities by donor, patient, doctor, blood bag, and other recognizable factors. A dynamic search will show donor information by nearest place and blood donation expire date. It will make easier to find and contact with donors when needed. There is add on facility of printing available as an option. Interface with grouping and testing machine provides user friendly communication. This application sends various auto-SMS for alerting donor and reminding 
location and time. Donor can send or receive message within this system. This system will automatically alert a donor before 24 hours of donating blood reminding the location and time by sending message when he/she is again eligible for donating blood after his/her previous donating. Donor can used this application through android based mobile phone. Donors login into the system with their e-mail Id and password. It allows donor to search others by location, blood group. They can get other donors details information.

\section{SYSTEM MODEL}

Blood Connect goes about the blood giveaway/donors with the individuals who require the blood adolescent run association \& give away free help \& exceptionally attempts to focus on poor people \& the penniless. Since commencement, the association has grown a great deal as far as working for this reason. The Existing System contains the specifications like, Asking for particular blood Group using their Contacts, Get the Donors details from the web sites and asking for blood, get the donor details from the mobile Applications, Requesting blood from Blood Bank. This android application encourages you discover individuals giving the blood your general vicinity. You can get touch with them through telephone number or email address. You can see the area of client guide \& enlist yourself with android application, you can get push notice the event which you're the blood aggregate matches with the need of the blood. In this system, users can search donors and make request for blood.

The Proposed System aims at Blood Bank record keeping has been carried out manually over the past decades using paper file management system which is slow for information retrieval and processing and also prone to errors in an emergency situation. This research work solves the above-mentioned problem with the development of both web-based and Android-based blood bank information retrieval system. The web application is used by various blood banks system administrators to update their available blood inventory information and the mobile application which has the mobile search engine is used to search for blood supplies from the registered blood banks. For blood to be in more excessive for usage at any time for those that require it as a result of blood donation it has to be gathered, stored and preserved for later use, this is called blood bank for transfusion. Blood Transfusion is the process of receiving blood into person circulation intravenously through the vein.

Transfusions are used for various medical conditions to replace lost components of the blood. Past decades, transfusion takes place by replacing the whole blood that was used but in this modern days, the practice of transfusion replaces only the components of the blood that was lost such as red blood cells, white blood cells, blood plasma, clotting factor, and platelets. The blood groups $\mathrm{A}, \mathrm{B}$ and $\mathrm{O}$ was discovered by Landsteiner during a laboratory experiment which he mixed blood samples taken from his staff when he then established the basic principle of $\mathrm{A}, \mathrm{B}$ and $\mathrm{O}$ compatibility.

\section{PROPOED SYSTEM IMPLEMENTATION}

Our application has two modes (i.e., donor and requester) to interact with the proposed 'blut' application. In voluntary donor mode, system will ask necessary information about the name, surname, user name, password, city, age and blood group. In case of requester mode, application ask patient , name, age, blood type, urgency of blood, hospital name, and contact information and optional small note. It can be dfined that our system starts from user registration and then classify the users as blood donors or requester. Blood requester can broadcast the blood 
request and donor will access this request anywhere anytime through cloud server. Volunteer donor will response to the request Requester will be notified about it.

A blood requester/recipient is require to register with our proposed blut application by specifying required blood group, hospital and type of urgency. The cloud server is responsible to broadcast the information to all the registered voluntary blood donors. We defmed two way communication scenario in our proposed system. Firstly, recipient request the blood donation along urgency status either high, normal or low. Any available volunteer blood donor can response the requested blood and requester will get the notification message about the available volunteer donor. Secondly, blut application will update the blood request status as complete for all other registered users. In the system, one of the donor profile along all required Infonnation. She can access the Requester information about the blood and also make search about the specific city or blood group.

A requester made a blood request about blood group "A-" and asking for Donation with short note message Once He made a request all the register donors get the alert about this broadcasted information. We showed that the system is applicable in the real-life scenario to make sure timely access of the blood donation. In the proposed architecture, voluntary blood donor is viewed as an intelligent agent that receive the information alert about the requested blood through a smartphone application.

\section{a. Dashboard}

The Dashboard consist of various modules such as Profile, Find Donor, Donate, Blood Bank, My Requests, Notifications, Details, about us. It shows the rating and points of the user.

\section{b. Login/register}

The login module will consist of the various entity such as mobile number, login password, login button and forgot password or register if the user has not registered himself in the app. If the user is not already registered, they can use Register instead of login.

\section{c. Profile}

The user profile page is the most direct way for people to know each other, and it is also a symbol of personality. It stores and shows the stored user data.

\section{d. Donate Blood (Register) and Edit Profile}

This module will consist of the donor registration, i.e. the registration of the donor will be done here and all the validation and verification process will take place in this sector in the module. Record keeping is another important function of registration offices and these records are permanent for all practical purposes. "Edit Profile" on your "Profile" page will enable you to change your name, bio, location. This controls your public and private information. Settings enables you to change your password, as well as manage your email addresses and any contributions you have started.

\section{e. Find Donor and Blood Bank}

In donor search the recipient has to select the required blood group. If the donor has donated blood within 6 months his data will not show to the Requester. Requester can also contact the nearest donor via GPS location. It shows the blood banks that are in your nearby location. It shows the details of blood banks such as Blood bank name, Location, Contact information. 


\section{CONCLUSION}

Blut is one of the best possible concept for the provision of HealthCare services and improve quality of life. This paper presented the conceptual design and prototype development of Blut application for blood donation. We investigate the requirements in tens of communication, storage, processing and smart phone development platform to make it an acceptable solution. We believe that our application is ubiquitous solution and may provide timely access to the blood donors and requester to handle the emergency situation. . Acknowledgment is that it gives away us the extra- ordinary delight within this exhibiting undertaking report titled "Blood Bank"\& one wishes to offer our huge thanks to the population which gave us important learning \& provision in culmination of this particular venture. Further, this android application can be tinted with free manual area, following of contributors \& recipients. Checking the authenticity of the benefactor must be possible with some more confirmed process. The distribution of the message or telecom of the promotion process might be in future presented for all the prominent android based life rather than just on social media like Facebook, Whatsapp, and Telegram etc. The database executive for this android application depends on the Firebase Parse server which can be taken into consideration by some best database servers. The database can be relocated to the cloud servers which can really expand proficiency of this undertaking.

\section{REFERENCES}

[1]. Williamson, M. Lorna, and D. V. Devine. "Challenges in the management of the blood supply. The Lancet 381, vol. no. 9880, pp. 1866-1875, 2013.

[2]. S. Venugopal, 1. Broberg, and 1. Brandic. "Cloud computing and emerging IT platforms:
Vision, hype, and reality for delivering computing as the 5th utility," Journal of Future Generation Computer Systems, vol. 25, no. 6, pp. 599-616, 2009.

[3]. K. Karagiannaki, S. Chonianakis, E. Patelarou, A. Panousopoulou. and M. Papadopouli. "mMamee: A mHealth Platform for Monitoring and Assessing Maternal Environmental Exposure." In 28th IEEE International Symposium on Computer-Based Medical Systems (CBMS), pp. 163-168,2015.

[4]. Jenipha, T.H. and Backiyalakshmi, R., 2014. Android blood donor life saving application in cloud computing. American Journal of Engineering Research (AJER), 3(02), pp.105108.

[5]. Mittal, N. and Snotra, K., 2017, October. Blood bank information system using Android application. In 2017 Recent Developments in Control, Automation \& Power Engineering (RDCAPE) (pp. 269-274). IEEE.

[6]. Casabuena, A., Caviles, R., De Vera, J.A., Flores, K.G., Catacutan-Bangit, A., Manuel, R., Bermudez, J.R. and Guadaña, R.R., 2018, October. BloodBank PH: A Framework for an Android-based Application for the Facilitation of Blood Services in the Philippines. In TENCON 2018-2018 IEEE Region 10 Conference (pp. 1637-1641). IEEE.

[7]. Ramadhan, M.N.S., Amyus, A., Fajar, A.N., Sfenrianto, S., Kanz, A.F. and Mufaqih, M.S., 2019, July. Blood Bank Information System Based on Cloud Computing In Indonesia. In Journal of Physics: Conference Series (Vol. 1179, No. 1, p. 012028). IOP Publishing.

[8]. Adsul, A.C., Bhosale, V.K. and Autee, R.M., 2018, January. Automated blood bank system using Raspberry PI. In 2018 2nd International Conference on Inventive Systems and Control (ICISC) (pp. 252-255). IEEE. 
[9]. Pande, S., Mate, S., Mawal, P., Jambulkar, A. and More, N.S., 2018. E-blood bank application using cloud computing. International Research Journal of Engineering and Technology (IRJET), 5(2).

[10]. Fahad, A.A.A., 2019. Design and implementation of blood bank system using web services in cloud environment. International Journal of MC Square Scientific Research, 11(3), pp.09-16.

\section{Cite this article as :}

Sajith T, Santhose D, Senthalan S, Vasanth V, "Blut : Blood Donation Application", International Journal of Scientific Research in Computer Science, Engineering and Information Technology (IJSRCSEIT), ISSN : 2456-3307, Volume 7 Issue 2, pp. 335-341, March-April 2021. Available at doi : https://doi.org/10.32628/CSEIT217275

Journal URL : https://ijsrcseit.com/CSEIT217275 